\title{
Title: Cancer stem cells and brain tumors.
}

Ana Perez-Castillo*, Diana Aguilar-Morante, Jose A. Morales-Garcia and Jorge Dorado.

Instituto de Investigaciones Biomédicas, CSIC-UAM and Centro de Investigación Biomédica en Red sobre Enfermedades Neurodegenerativas (CIBERNED), Arturo Duperier, 4. 28029-Madrid, Spain.

*Correspondence to aperez@iib.uam.es

\begin{abstract}
Besides the role that normal stem cells play in organogenesis, cancer stem cells are thought to be crucial for tumorigenesis. Most current research on human tumors is focused on the molecular and cellular analysis of the bulk tumor mass. However, evidence in leukemia and, more recently, in solid tumors suggests that the tumor cell population is heterogeneous. During the last years, several groups have described the existence of a cancer stem cell population in different brain tumors. These neural cancer stem cells (NCSC) can be isolated by cell sorting of dissociated suspensions of tumor cells for the neural stem cell marker CD133. These CD133 ${ }^{+}$cells, which also express nestin, an intermediate filament that is another neural stem cell marker, represent a minority fraction of the entire brain tumor population. The stem-like cancer cells appear to be solely responsible for propagating the disease in laboratory models. A promising new approach to treat glioblastoma proposes targeting cancer stem cells. Here, we summarize progress in delineating NCSC and the implications of the discovery of this cell population in human brain tumors.
\end{abstract}

\section{Introduction}

The cancer stem cell hypothesis proposes that cancers derive from a small fraction of cancer cells that constitute a reservoir of self-sustained cells with the exclusive ability to self-renew and maintain the tumor. There is increasing evidence that malignant tumors, such as leukemias, breast cancer and brain cancers, contain cells that maintain the characteristics of tissue-specific stem cells. These stem-like tumor 
cells are bestowed with dysregulated potential for self-renewal, excessive proliferation, and aberrant differentiation into a heterogeneous progeny of cancer cells culminating in the intra-tumor heterogeneity. Rapidly accumulating evidence from various laboratories has shown that in several forms of human cancer, only a minority subpopulation of cancer cells are able to form new tumors when transplanted into immunodeficient mice. The population of cells selectively endowed with tumorigenic capacity can be purified from whole tumor tissues by virtue of a surface marker expression profile, and is currently defined as the "cancer stem cell" population. Cancer stem cells have been identified from various solid tumors including breast $\left(\mathrm{CD} 44^{+}\right.$and $\left.\mathrm{CD} 24^{-/ \text {low }}\right)$, colorectal $\left(\mathrm{CD}_{133}{ }^{+}\right)$, ependymoma $\left(\mathrm{CD} 133^{+}, \mathrm{Nestin}^{+}\right.$and $\left.\mathrm{BLBP}^{+}\right)$and glioblastoma $\left(\mathrm{CD} 133^{+}\right)$ (Al-Hajj et al., 2003; Singh et al., 2004; Taylor et al., 2005; O'Brien et al., 2007). Currently, an intense debate is ongoing as to whether cancer stem cells originate from adult stem cells or from mature, committed progenitors and/or even terminally differentiated cells that have abnormally acquired self-renewal capacity(Singh et al., 2004). It is also suggested that niche cells could also be a primary target for the carcinogenic insult to adult stem cells, thereby inciting a tumorigenic response (Tlsty and Hein, 2001). Thus, the molecular mechanisms underlying the genesis of cancer stem cells are still obscure and identification of unique cell surface markers for cancer stem cell isolation could provide new tools to address these questions and allow for further molecular and functional characterizations.

High-grade gliomas, which include glioblastoma (GBM) and anaplastic astrocytoma, are among the most common intrinsic brain tumors in adults and are nearly uniformly fatal. While there has been progress in understanding the molecular genetics of these tumors(Kitange et al., 2003), the cell types of origin are still uncertain, and the molecular determinants of disease aggressiveness are not well understood. A better understanding of the cellular origin and molecular pathogenesis of these tumors may identify new targets for treatment of these neoplasms. Until recently, GBMs were presumed to arise from glial cells residing within the brain parenchyma However, recent evidence suggests that neural stem cells can be an alternate cellular origin of gliomas (Singh et al., 2003; Caussinus and Gonzalez, 2005; Zhu et al., 2005). In fact, recent evidence demonstrates that neural stem cells can give rise to neoplasms that recapitulates the histopathological hallmarks of human gliomas (Bachoo et al., 2002; Uhrbom et al., 2002). 
Adult neural stem cells are cells in the adult nervous system that can self-renew and differentiate into all types of neural cells, including neurons, astrocytes, and oligodendrocytes (Gage, 2000). In the adult human forebrain, the majority of neurons are born by the early postnatal period, but it has been demonstrated that neurons continue to arise in two niches of the adult brain, the subventricular zone (SVZ) of the lateral ventricle and in the subgranular zone (SGZ) of the dentate gyrus (Luskin et al., 1997; Gage et al., 1998). In the hippocampus, granule neurons arise in the subgranular zone of the dentate gyrus. Progenitor cells in the SVZ migrate to the olfactory bulb (OB) through the rostral migratory stream (RMS) where they differentiate into granule and periglomerular neurons of the OB (Figure 1). Both cell-extrinsic and cell-intrinsic factors have been shown to influence the maintenance and regulation of the neurogenic system in vivo (Ostenfeld and Svendsen, 2003). A number of factors, including the brain-derived neurotrophic factor, insulin-like growth factor-1, epidermal growth factor (EGF) and the basic fibroblast growth factor (bFGF), have been shown to affect the proliferation and differentiation of precursor cell populations (Bartlett et al., 1995; Johe et al., 1996). This population of neural stem cells has distinct features such as the capacity of self-renewing, multipotency, asymmetric division, and express characteristics markers such as nestin, a cystoskeletal protein, CD133, a cell surface marker of normal neural ítem cells, and Notch. The demonstration that the adult human brain contains an abundant source of neural stem cells and that GBMs contain tumorigenic neural stem-like cells indicate that neural stem cells are a plausible origin of human gliomas and have given rise to speculation that more effective therapies will result from approaches aimed at targeting the stem cell-like component of GBM (Ignatova et al., 2002; Berger et al., 2004; Oliver and Wechsler-Reya, 2004; Fomchenko and Holland, 2005). Glioblastoma tumor stem cells possess the capacity to self-renewal leading to daughter cells with the same predisposition for replication as the parental cells, and the capacity to recapitulate the generation of a growing tumor (Clarke, 2004). These capacities have been shown for $\mathrm{CD}_{133^{+}}$cells isolated from glioblastoma (Galli et al., 2004). A small number of $\mathrm{CD}_{133^{+}}$cells are sufficient for the formation of glioblastoma in immunodeficient mice. The resulting primary xenograpgh consisting of a minority of $\mathrm{CD}_{133^{+}}$cells and a majority of $\mathrm{CD} 133^{-}$cells is a phenocopy of the patient's tumor (Singh et al., 2004). 
In addition to possessing the fundamental stem cell properties of self-renewal and multi-potency, glioblastoma stem cells share other characteristics with neural stem cells. They were first isolated from tumors by virtue of the expression of CD133 that marks neural stem and progenitor cells (Singh et al., 2004). The similarities in gene expression suggest that common cell signaling systems might operate in normal and malignant neural stem cells. These phenotypic and functional similarities suggest that glioblastoma stem cells might arise from normal neural stem cells that retain selfrenewal properties but acquire mutations necessary for tumorigenicity. Indeed, deletion of $N f 1$ and Trp53 from neural stem cells in mice initiates gliomagenesis in the subventricular zone (SVZ), where neural stem cells reside (Zhu et al., 2005). However, whether human glioblastoma stem cells arise from mutated neural stem cells or a more mature cell type that acquires self-renewal capacity remains to be determined.

\section{The stem cell niche}

It has been long recognized that normal stem cells of various tissues are tightly regulated by the immediate microenvironment or stem cell niche(Moore and Lemischka, 2006). Consequently, an important question is whether glioblastoma stem cells also depend on cues from the environment for survival. Stem cell niches are not merely repositories for stem cells, but are complex dynamic entities that actively control stem cell function (Scadden, 2006) regulating stem cell-renewal and fate. This microenvironment of stem cells is known to help maintain the cells in a "quiescent" state and preserve their potential to proliferate and differentiate (Fuchs et al., 2004; Ailles and Weissman, 2007). Direct genetic alterations or dysregulated crosstalk between signaling pathways of the CSCs and the cells of their microenvironment have been implicated as important determinants of functional tumor microenvironment preceding cancer development (Moinfar et al., 2000; Lopez-Otin and Matrisian, 2007). As commented in the Introduction, studies conducted during the last years have identified stem cells with regenerative capacity in the subventricular zone and the subgranular zone of the dentate gyrus. The central structural element of the neural stem cell niche is provided by capillaries within these zones. This organization places the stem cells in close proximity to endothelial and other vascular cells, facilitating communication among these cell types. The existence of niches extends to tumor cells as well. The tumor microenvironment, composed of nonepithelial stromal cells 
increasingly is shown to be essential for tumor growth (Figure 2) (Kenny et al., 2007). Neural cancer stem cells have been shown to lie within a vascular microenvironment. In this regard, Calabrese et al recently provided convincing evidence that stem cells from various brain tumors, including glioblastoma, are indeed maintained within vascular niches that mimic the neural stem cell niche (Calabrese et al., 2007). Using coimmunofluorescence and multi-photon laser scanning microscopy, they showed first that $\mathrm{CD} 133^{+} / \mathrm{Nestin}^{+}$tumor cells are closely associated with vasculature. Furthermore, increasing the number of endothelial cells and blood vessels in xenografts augmented the NCSC population and the rate of tumor growth. Clinical trials of the anti-angiogenic drug bevacizumab (Vredenburgh et al., 2007) have demonstrated a potent anti-tumor effect in patients with glioblastoma. This effect could be the result of a depletion of the tumor blood supply. However, the presence of a glioblastoma stem cell niche would imply that this drug might also function to disrupt stem cell maintenance. In this regard, Calabrese and colleagues showed that treating glioblastoma-bearing mice with bevacizumab depleted tumor blood vessels and caused a significant reduction both in the NCSC population and tumor growth rate. Interestingly, this treatment did not alter the proliferation or survival of most of the cells in the tumor, suggesting that the drug was specifically acting on the cancer stem cells. The notion that cancer stem cells exist in aberrant cell niches is an attractive one. A recent study of human gliomas suggests that bone morphogenic proteins, which are niche-derived regulators of neural stem cell fate might also regulate the differentiation status of cancer stem cells (Piccirillo et al., 2006). Therefore, the tumor microenvironment offers a novel approach to treatment through the targeting of cells inside the tumor niche.

\section{Identifying Glioblastoma Stem Cells}

Correctly identifying stem cells in vivo remains the biggest obstacle to progress in understanding stem cell biology. The identification of reliable markers will allow prospective isolation and characterization of a pure population of CSCs, not just a population of cells containing CSCs. Normal stem cells and their neighboring cells within tissues can rarely be located by histological methods. Some properties that have been widely assumed to mark stem cells, such as preferential bromodeoxyuridine (BrdU) label retention (caused by an expected tendency of stem cells to divide more slowly than many of their progeny) have frequently proven to be unreliable without the 
use of other markers (Crittenden et al., 2006; Barker et al., 2007; Kiel et al., 2007). The "side population" (SP) is defined by Hoechst dye exclusion in flow cytometry and has been commonly used as one of the methods of enriching for cancer stem cells in glioblastomas (Kondo et al., 2004) and also in other types of tumor cells. Goodell et al. have demonstrated that the exclusion of Hoechst 33342 dye by SP cells is a dynamic process involving the multidrug resistance transporter 1 (MDR1), a member of the ABC transporter transmembrane proteins (Goodell et al., 1996; Hirschmann-Jax et al., 2004). However, MDR1 cannot be taken as a single marker to identify and isolate SP cells, and additional transporters should be analyzed.

Much work has been carried out on brain tumor stem cells enriched by the cell surface marker, CD133. It is unclear at this time whether the SP overlaps with the CD133 population, but both markers have been shown to be highly enriched in neurosphere-forming capacity (Yuan et al., 2004; Beier et al., 2007), one of the defining characteristics of neural stem cells and progenitors (Figure 3). Recently, several groups have isolated NCSC from glioblastomas (Singh et al., 2003). They cultured dissociated tumor samples and expanded the cells on a defined, serum-free medium containing fibroblast growth factor and epidermal growth factor. These cells form floating aggregates (neurospheres) just as normal neural stem cells do in the same conditions. These neurospheres retain the self-renewing capacity and expressed neural stem cell markers, such as nestin, CD133, and Notch. Such aggregates, highly enriched in longterm, self-renewing multipotent cells in vitro, formed malignant tumors when transplanted in vivo in immunodeficient mice. These findings indicate that glioblastomas contain cancer initiating neural stem-like cells, which can be identified by their staining with CD133 (Singh et al., 2003; Singh et al., 2004). Furthermore, it has been recently shown that CD133 expression correlates with patient survival in gliomas, lending support to the current cancer stem cell hypothesis (Zeppernick et al., 2008). These authors have found, using a large panel of human glioma samples, frequencies of $\mathrm{CD} 33^{+}$cells to increase with tumor grade, with many glioblastomas containing $>25 \%$ positive cells. In contrast, tissue sections of many WHO grade tumors were devoid of immunoreactive cells, probably indicating a low frequency of CSCs in these less malignant tumors. These findings provide strong valuable evidence for the CSC hypothesis and the clinical relevance of the CD133-positive cell population in glioblastomas. 
Another important trait of brain tumor stem cells is the signaling trough Notch receptor. Notch signaling is strongly activated in primary human gliomas and in several glioma cell lines (Pahlman et al., 2004) where its depletion reduces tumor proliferation (Purow et al., 2005). Moreover, transfection of downstream mediators of the Notch pathway results in an increase in the growth and sphere formation of human glioma $\mathrm{CD}_{133^{+}}$cells, indicating that Notch signaling is essential for the maintenance and proliferation of the tumor stem cell population (Zhang et al., 2008). A similar effect has been observed in medulloblastoma stem cells, where loss of tumor forming capacity is attributed to depletion of cancer stem cells in response to Notch signalling blockade (Fan et al., 2006). This data are in agreement with the studies in non-neoplasic stem cells that attribute Notch signalling the role of inhibiting neuronal differentiation and maintaining the neural progenitor pool (Yoon and Gaiano, 2005).

\section{Neural cancer stem cells as therapeutic targets}

Malignant primary brain tumors are characterized by a short median survival and almost 100\% tumor-related mortality. Therefore, this brain tumor remains one of the most lethal forms of human cancer. Glial neoplasms are the most frequent primary intracranial neoplasms in man accounting for more than $60 \%$ of all primary brain tumors. Although glioblastomas, the most malignant of these, rarely spread outside the nervous system, they infiltrate crucial structures in the brain, preventing curative surgical resection. Radiation and chemotherapy offer only modest benefits and remain essentially palliative (Stupp et al., 2005). Conventional chemotherapy and/or radiation therapies are not usually designed to target a specific cell subpopulation, and their clinical efficacy is measured by their capacity to induce regression of bulk tumor lesions. It is therefore difficult to know whether traditional anti-tumor treatments are able to target cancer stem cells, which are thought to be resistant to such treatments (Guzman et al., 2002; Bao et al., 2006). If glioblastomas are maintained by NCSCs, cells that are characterized by low rates of division and proliferation, it is clear that therapies such as chemotherapy or radiation, which target actively cycling cells, are doubtful to be effective, therefore it is unlikely that existing treatments will ever cure most patients with glioblastoma. Thus, the concept of cancer stem cells provides an interesting conceptual framework to interpret the phenomenon of tumor relapse as well 
as the heterogeneity found inside tumors in terms of aberrant cell proliferation and differentiation (Reya et al., 2001). Cancer treatment has traditionally been based on the implicit assumption that human cancer populations are homogeneous. Cancer is resilient to treatment because malignant cells survive chemotherapy and radiation or avoid immune surveillance of endogenous cytotoxic $\mathrm{T}$ cells and natural killer cells. Since cancer stem cells have a capacity for unlimited self-renewal, as well as the ability to initiate and drive tumor progression in an animal model (Singh et al., 2004; O'Brien et al., 2007) they would seem the most probable candidates responsible for tumor chemoresistance and recurrence.

In fact, recent investigations in the field of brain and breast cancers implicate cancer stem cells in radiation resistance (Bao et al., 2006; Phillips et al., 2006; Woodward et al., 2007). Bao et al. demonstrated that radiation resistance in highly malignant gliomas (GBM) is most likely mediated by tumor stem cells (Bao et al., 2006). This work show that radiation treatment fails in the long run because it cannot kill the subpopulation of $\mathrm{CD} 133^{+}$tumor-initiating cells. They showed that $\mathrm{CD} 133^{+}$ cancer stem cells contributed to glioma resistance through preferential activation of DNA damage checkpoint response and an increase in DNA repair capacity compared with CD133- tumor cells. The radioresistance of CD133 glioma stem cells could be reversed with a specific inhibitor of Chk1 and Chk2 checkpoint kinases, which are closely associated with cellular resistance to radiation, thereby providing a therapeutic advantage to reducing brain tumor occurrence. As the cell cycle of a normal stem cell is tightly controlled by the checkpoint to maintain genomic stability and integrity, the defective checkpoint responses associated with early cancer development (Bartkova et al., 2005; Gorgoulis et al., 2005) point to an abnormal checkpoint control as a potential contributor to the transformation of normal cells into cancer stem cells. Therefore, targeting the checkpoint response in $\mathrm{CD}_{133^{+}}$glioblastoma cells may help to overcome the radioresistance of this tumor. Further studies may confirm a rate-limiting role of DNA repair for the functionality of glioblastoma cells.

Also, Liu et al demonstrated an increased resistance of CD133-positive brain tumor stem cells in response to treatment with chemotherapeutic agents such as carboplatin, paclitaxel, and etoposide, compared to CD133-negative cells (Liu et al., 2006). These studies revealed a higher expression of the multidrug resistance gene 
BCRP1 and genes that inhibited apoptosis in the CD133-expressing cancer stem cells. The work also showed that CD133 expression was significantly higher in recurrent glioblastomas compared to their respective newly diagnosed tumors. These results suggest that, although chemotherapy kills most of the cells in a tumor, NCSCs remain viable and can then reappear due to their enhanced chemoresitance.

Regarding the clinical implications of cancer stem cells, Piccirillo et al. first showed that human glioblastoma cells expressed bone morphogenetic proteins (BMPs) and their cell surface receptors, BMPs being the soluble factors that normally induce neural precursor cells to differentiate into mature astrocytes, a subtype of brain cells called glial cells (Piccirillo et al., 2006). These authors showed that BMPs could also promote the differentiation of $\mathrm{CD}_{133}{ }^{+}$brain tumor stem cells, seriously weakening their tumor-forming ability. The results further imply that tumor populations at least partially retain a developmental hierarchy based on stem cells, and remain able to respond to the normal signals that induce them to mature. These findings should lead to renewed interest in devising therapies that promote the differentiation of cancer cells.

\section{Future directions}

In conclusion, although major questions remain unanswered concerning the origin and function of neural cancer stem cells, their existence in glioblastomas is a widely accepted hypothesis. How these NCSC control cell growth and cell-cycle progression of glioblastomas, however, is not yet clear. It is not clear whether exists a stem cellspecific machinery that controls growth and proliferation in a variety of stem cell lineages and why does stem cell proliferation get out of control when asymmetric cell division is compromised. Furthermore, what are the molecular events that occur when such a compromised stem cell becomes unresponsive to growth control signals? The striking discovery of stem cell lineages in many tumors, including glioblastomas, might lead to the identification of entirely new mechanisms for stem cell control. All the data obtained so far suggest that in the coming years, NCSCs will be identified as a powerful new potential therapeutic target, and knowledge of the detailed biology and clinical

significance of this noticeably defined population will provide further support for the NCSC hypothesis. Additionally, current efforts focus on the evaluation of target 
expression profiles in neural cancer stem cells in glioblastomas and on the potential of these cells to escape therapy. Ultimately, focusing research efforts on the NCSC may drive important advances in our understanding of glioblastoma biology and developing potential cures for this devastating disease.

\section{Acknowledgments}

Work in my lab is supported by the Ministerio de Educacion y Ciencia grants SAF200406263-CO2-01 and SAF2007-62811 and the Comunidad de Madrid grant GR/SAL/0033/2004.

\section{References}

Ailles LE, Weissman IL (2007) Cancer stem cells in solid tumors. Curr Opin Biotechnol 18:460-466.

Al-Hajj M, Wicha MS, Benito-Hernandez A, Morrison SJ, Clarke MF (2003) Prospective identification of tumorigenic breast cancer cells. Proc Natl Acad Sci U S A 100:39833988.

Bachoo RM, Maher EA, Ligon KL, Sharpless NE, Chan SS, You MJ, Tang Y, DeFrances J, Stover E, Weissleder R, Rowitch DH, Louis DN, DePinho RA (2002) Epidermal growth factor receptor and Ink4a/Arf: convergent mechanisms governing terminal differentiation and transformation along the neural stem cell to astrocyte axis. Cancer Cell 1:269-277.

Bao S, Wu Q, McLendon RE, Hao Y, Shi Q, Hjelmeland AB, Dewhirst MW, Bigner DD, Rich JN (2006) Glioma stem cells promote radioresistance by preferential activation of the DNA damage response. Nature 444:756-760.

Barker N, van Es JH, Kuipers J, Kujala P, van den Born M, Cozijnsen M, Haegebarth A, Korving J, Begthel H, Peters PJ, Clevers H (2007) Identification of stem cells in small intestine and colon by marker gene Lgr5. Nature 449:1003-1007. 
Bartkova J, Horejsi Z, Koed K, Kramer A, Tort F, Zieger K, Guldberg P, Sehested M, Nesland JM, Lukas C, Orntoft T, Lukas J, Bartek J (2005) DNA damage response as a candidate anti-cancer barrier in early human tumorigenesis. Nature 434:864-870.

Bartlett PF, Richards LR, Kilpatrick TJ, Talman PT, Bailey KA, Brooker GJ, Dutton R, Koblar SA, Nurcombe V, Ford MO, et al. (1995) Factors regulating the differentiation of neural precursors in the forebrain. Ciba Found Symp 193:85-99; discussion 117-126.

Beier D, Hau P, Proescholdt M, Lohmeier A, Wischhusen J, Oefner PJ, Aigner L, Brawanski A, Bogdahn U, Beier CP (2007) CD133(+) and CD133(-) glioblastomaderived cancer stem cells show differential growth characteristics and molecular profiles. Cancer Res 67:4010-4015.

Berger F, Gay E, Pelletier L, Tropel P, Wion D (2004) Development of gliomas: potential role of asymmetrical cell division of neural stem cells. The lancet oncology 5:511-514.

Calabrese C, Poppleton H, Kocak M, Hogg TL, Fuller C, Hamner B, Oh EY, Gaber MW, Finklestein D, Allen M, Frank A, Bayazitov IT, Zakharenko SS, Gajjar A, Davidoff A, Gilbertson RJ (2007) A perivascular niche for brain tumor stem cells. Cancer Cell 11:6982.

Caussinus E, Gonzalez C (2005) Induction of tumor growth by altered stem-cell asymmetric division in Drosophila melanogaster. Nat Genet 37:1125-1129.

Clarke MF (2004) Neurobiology: at the root of brain cancer. Nature 432:281-282.

Crittenden SL, Leonhard KA, Byrd DT, Kimble J (2006) Cellular analyses of the mitotic region in the Caenorhabditis elegans adult germ line. Mol Biol Cell 17:3051-3061.

Fan X, Matsui W, Khaki L, Stearns D, Chun J, Li YM, Eberhart CG (2006) Notch pathway inhibition depletes stem-like cells and blocks engraftment in embryonal brain tumors. Cancer Res 66:7445-7452.

Fomchenko EI, Holland EC (2005) Stem cells and brain cancer. Exp Cell Res 306:323329. 
Fuchs E, Tumbar T, Guasch G (2004) Socializing with the neighbors: stem cells and their niche. Cell 116:769-778.

Gage FH (2000) Mammalian neural stem cells. Science 287:1433-1438.

Gage FH, Kempermann G, Palmer TD, Peterson DA, Ray J (1998) Multipotent progenitor cells in the adult dentate gyrus. J Neurobiol 36:249-266.

Galli R, Binda E, Orfanelli U, Cipelletti B, Gritti A, De Vitis S, Fiocco R, Foroni C, Dimeco F, Vescovi A (2004) Isolation and characterization of tumorigenic, stem-like neural precursors from human glioblastoma. Cancer Res 64:7011-7021.

Goodell MA, Brose K, Paradis G, Conner AS, Mulligan RC (1996) Isolation and functional properties of murine hematopoietic stem cells that are replicating in vivo. $\mathrm{J}$ Exp Med 183:1797-1806.

Gorgoulis VG, Vassiliou LV, Karakaidos P, Zacharatos P, Kotsinas A, Liloglou T, Venere M, Ditullio RA, Jr., Kastrinakis NG, Levy B, Kletsas D, Yoneta A, Herlyn M, Kittas C, Halazonetis TD (2005) Activation of the DNA damage checkpoint and genomic instability in human precancerous lesions. Nature 434:907-913.

Guzman ML, Swiderski CF, Howard DS, Grimes BA, Rossi RM, Szilvassy SJ, Jordan CT (2002) Preferential induction of apoptosis for primary human leukemic stem cells. Proc Natl Acad Sci U S A 99:16220-16225.

Hirschmann-Jax C, Foster AE, Wulf GG, Nuchtern JG, Jax TW, Gobel U, Goodell MA, Brenner MK (2004) A distinct "side population" of cells with high drug efflux capacity in human tumor cells. Proc Natl Acad Sci U S A 101:14228-14233.

Ignatova TN, Kukekov VG, Laywell ED, Suslov ON, Vrionis FD, Steindler DA (2002) Human cortical glial tumors contain neural stem-like cells expressing astroglial and neuronal markers in vitro. Glia 39:193-206. 
Johe KK, Hazel TG, Muller T, Dugich-Djordjevic MM, McKay RD (1996) Single factors direct the differentiation of stem cells from the fetal and adult central nervous system. Genes Dev 10:3129-3140.

Kenny PA, Lee GY, Bissell MJ (2007) Targeting the tumor microenvironment. Front Biosci 12:3468-3474.

Kiel MJ, He S, Ashkenazi R, Gentry SN, Teta M, Kushner JA, Jackson TL, Morrison SJ (2007) Haematopoietic stem cells do not asymmetrically segregate chromosomes or retain BrdU. Nature 449:238-242.

Kitange GJ, Templeton KL, Jenkins RB (2003) Recent advances in the molecular genetics of primary gliomas. Curr Opin Oncol 15:197-203.

Kondo T, Setoguchi T, Taga T (2004) Persistence of a small subpopulation of cancer stem-like cells in the C6 glioma cell line. Proc Natl Acad Sci U S A 101:781-786.

Liu G, Yuan X, Zeng Z, Tunici P, Ng H, Abdulkadir IR, Lu L, Irvin D, Black KL, Yu JS (2006) Analysis of gene expression and chemoresistance of CD133+ cancer stem cells in glioblastoma. Mol Cancer 5:67.

Lopez-Otin C, Matrisian LM (2007) Emerging roles of proteases in tumour suppression. Nature reviews 7:800-808.

Luskin MB, Zigova T, Soteres BJ, Stewart RR (1997) Neuronal progenitor cells derived from the anterior subventricular zone of the neonatal rat forebrain continue to proliferate in vitro and express a neuronal phenotype. Mol Cell Neurosci 8:351-366.

Moinfar F, Man YG, Arnould L, Bratthauer GL, Ratschek M, Tavassoli FA (2000) Concurrent and independent genetic alterations in the stromal and epithelial cells of mammary carcinoma: implications for tumorigenesis. Cancer Res 60:2562-2566.

Moore KA, Lemischka IR (2006) Stem cells and their niches. Science 311:1880-1885.

O'Brien CA, Pollett A, Gallinger S, Dick JE (2007) A human colon cancer cell capable of initiating tumour growth in immunodeficient mice. Nature 445:106-110. 
Oliver TG, Wechsler-Reya RJ (2004) Getting at the root and stem of brain tumors. Neuron 42:885-888.

Ostenfeld T, Svendsen CN (2003) Recent advances in stem cell neurobiology. Adv Tech Stand Neurosurg 28:3-89.

Pahlman S, Stockhausen MT, Fredlund E, Axelson H (2004) Notch signaling in neuroblastoma. Semin Cancer Biol 14:365-373.

Phillips TM, McBride WH, Pajonk F (2006) The response of CD24(-/low)/CD44+ breast cancer-initiating cells to radiation. J Natl Cancer Inst 98:1777-1785.

Piccirillo SG, Reynolds BA, Zanetti N, Lamorte G, Binda E, Broggi G, Brem H, Olivi A, Dimeco F, Vescovi AL (2006) Bone morphogenetic proteins inhibit the tumorigenic potential of human brain tumour-initiating cells. Nature 444:761-765.

Purow BW, Haque RM, Noel MW, Su Q, Burdick MJ, Lee J, Sundaresan T, Pastorino S, Park JK, Mikolaenko I, Maric D, Eberhart CG, Fine HA (2005) Expression of Notch-1 and its ligands, Delta-like-1 and Jagged-1, is critical for glioma cell survival and proliferation. Cancer Res 65:2353-2363.

Reya T, Morrison SJ, Clarke MF, Weissman IL (2001) Stem cells, cancer, and cancer stem cells. Nature 414:105-111.

Scadden DT (2006) The stem-cell niche as an entity of action. Nature 441:1075-1079.

Singh SK, Clarke ID, Terasaki M, Bonn VE, Hawkins C, Squire J, Dirks PB (2003) Identification of a cancer stem cell in human brain tumors. Cancer Res 63:5821-5828.

Singh SK, Hawkins C, Clarke ID, Squire JA, Bayani J, Hide T, Henkelman RM, Cusimano MD, Dirks PB (2004) Identification of human brain tumour initiating cells. Nature 432:396-401. 
Stupp R, Mason WP, van den Bent MJ, Weller M, Fisher B, Taphoorn MJ, Belanger K, Brandes AA, Marosi C, Bogdahn U, Curschmann J, Janzer RC, Ludwin SK, Gorlia T, Allgeier A, Lacombe D, Cairncross JG, Eisenhauer E, Mirimanoff RO (2005) Radiotherapy plus concomitant and adjuvant temozolomide for glioblastoma. The New England journal of medicine 352:987-996.

Taylor MD, Poppleton H, Fuller C, Su X, Liu Y, Jensen P, Magdaleno S, Dalton J, Calabrese C, Board J, Macdonald T, Rutka J, Guha A, Gajjar A, Curran T, Gilbertson RJ (2005) Radial glia cells are candidate stem cells of ependymoma. Cancer Cell 8:323-335. Tlsty TD, Hein PW (2001) Know thy neighbor: stromal cells can contribute oncogenic signals. Curr Opin Genet Dev 11:54-59.

Uhrbom L, Dai C, Celestino JC, Rosenblum MK, Fuller GN, Holland EC (2002) Ink4aArf loss cooperates with KRas activation in astrocytes and neural progenitors to generate glioblastomas of various morphologies depending on activated Akt. Cancer Res 62:55515558.

Vredenburgh JJ, Desjardins A, Herndon JE, 2nd, Dowell JM, Reardon DA, Quinn JA, Rich JN, Sathornsumetee S, Gururangan S, Wagner M, Bigner DD, Friedman AH, Friedman HS (2007) Phase II trial of bevacizumab and irinotecan in recurrent malignant glioma. Clin Cancer Res 13:1253-1259.

Woodward WA, Chen MS, Behbod F, Alfaro MP, Buchholz TA, Rosen JM (2007) $\mathrm{WNT} /$ beta-catenin mediates radiation resistance of mouse mammary progenitor cells. Proc Natl Acad Sci U S A 104:618-623.

Yoon K, Gaiano N (2005) Notch signaling in the mammalian central nervous system: insights from mouse mutants. Nat Neurosci 8:709-715.

Yuan X, Curtin J, Xiong Y, Liu G, Waschsmann-Hogiu S, Farkas DL, Black KL, Yu JS (2004) Isolation of cancer stem cells from adult glioblastoma multiforme. Oncogene 23:9392-9400. 
Zeppernick F, Ahmadi R, Campos B, Dictus C, Helmke BM, Becker N, Lichter P, Unterberg A, Radlwimmer B, Herold-Mende CC (2008) Stem cell marker CD133 affects clinical outcome in glioma patients. Clin Cancer Res 14:123-129.

Zhang XP, Zheng G, Zou L, Liu HL, Hou LH, Zhou P, Yin DD, Zheng QJ, Liang L, Zhang SZ, Feng L, Yao LB, Yang AG, Han H, Chen JY (2008) Notch activation promotes cell proliferation and the formation of neural stem cell-like colonies in human glioma cells. Mol Cell Biochem 307:101-108.

Zhu Y, Guignard F, Zhao D, Liu L, Burns DK, Mason RP, Messing A, Parada LF (2005) Early inactivation of p53 tumor suppressor gene cooperating with NF1 loss induces malignant astrocytoma. Cancer Cell 8:119-130. 